\title{
DISTRIBUIÇÃO DE GEMINIVÍRUS NAS CULTURAS DO TOMATE E PIMENTÃo EM DOZE MUNICÍPIOS DO SUBMÉDIO DO VALE SÃO FRANCISCO
}

\author{
MIRTES F. LIMA ${ }^{1}$, ISABEL C. BEZERRA ${ }^{2}$, SIMONE G. RIBEIRO ${ }^{3} \&$ ANTÔNIO C. DE ÁVILA \\ 'Embrapa Semi-Árido Cx. Postal 23 CEP 56300-970 Petrolina-PE (mflima@cpatsa.embrapa.br); ${ }^{2}$ Embrapa Hortaliças \\ Cx. Postal 218, CEP 70359-970 Brasília-DF; ${ }^{3}$ Embrapa Recursos Genéticos e Biotecnologia Cx. Postal 2372, \\ CEP 70770-900 Brasília-DF
}

(Aceito para publicação em 05/12/2000)

Autor para correspondência: Mirtes Freitas Lima

LIMA, M.F., BEZERRA, I.C., RIBEIRO, S.G. \& DE ÁVILA, A.C. Distribuição de geminivírus nas culturas do tomate e pimentão em doze municípios do Submédio do Vale São Francisco. Fitopatologia Brasileira 26:81-85. 2001.

\section{RESUMO}

Em 1996 e 1997, observaram-se sintomas de viroses causadas por geminivírus transmitidos por mosca branca em plantas de tomateiro (Lycopersicon esculentum) e pimentão (Capsicum annuum) no Submédio do Vale São Francisco, situado nos Estados de Pernambuco e Bahia. De outubro de 1996 a dezembro de 1998, foram coletadas 1.368 amostras foliares de tomateiro e 194 de pimentão, exibindo sintomas similares àqueles causados por geminivírus, em 104 e 16 plantios, respectivamente, de 12 municípios dessa região e em dois municípios vizinhos. A incidência de geminiviroses nas áreas amostradas foi estimada entre 5 e100\% para tomate e entre 10 e $20 \%$ para pimentão. A detecção de geminivírus nas amostras foi feita por "dot blot" ou "squash blot" utilizando-se sondas heterólogas. Para as amostras de tomate, a sonda foi constituída pelos componentes A completos de dois isolados, um de Bean golden mosaic virus (BGMV) do Brasil e outro de Bean golden yellow mosaic virus (BGYMV) da Guatemala, enquanto que para pimentão, esta foi constituída apenas por um fragmento do componente A de um isolado de geminivírus de tomate do Distrito Federal. Do total de 1562 amostras analisadas, em $908(58,1 \%)$ confirmouse a presença de geminivírus, sendo $823(60,2 \%)$ de tomate e $85(43,8 \%)$ de pimentão. A presença de plantas infetadas foi detectada em todos os 120 plantios, com incidência entre 20 e 100\%, indicando ampla disseminação de geminivírus nestas culturas no Submédio do Vale São Francisco.

Palavras-chave: Lycopersicon esculentum, Capsicum annuum, epidemiologia, Begomovirus.

\section{ABSTRACT \\ Distribution of geminivirus in tomato and sweet pepper crops in twelve counties of the Lower Basin of San Francisco Valley}

In 1996 and 1997, whitefly-transmitted geminivirus symptoms were observed in tomato (Lycopersicon esculentum) and sweet pepper (Capsicum annuum) plants in the Lower basin of San Francisco Valley, located in the states of Pernambuco and Bahia, Northeastern Brazil. One thousand three hundred and sixty-eight leaf samples of tomato and 194 pepper leaf samples showing similar symptoms to those caused by geminivirus were randomly collected from October 1996 to December 1998 in 104 and 16 fields, respectively, from 12 counties of that region and two neighboring counties. The incidence of symptomatic plants was estimated from 5 to $100 \%$ in tomato and 10 to $20 \%$ in sweet pepper fields. For geminivirus detection, dot or squash-blots were hybridized with heterologous probes. For tomato, the probe consisted of full-length DNA-A components of Bean golden mosaic virus (BGMV) from Brazil and Bean golden yellow mosaic virus (BGYMV) from Guatemala, while for sweet pepper it consisted of a fragment of the DNA-A component of an isolate from tomato found in the Federal District. Out of 1,562 collected samples, $908(58.1 \%)$ tested positive for geminivirus, 823 $(60.2 \%)$ on tomato and $85(43.8 \%)$ on sweet pepper. The presence of infected plants was detected in all 120 fields with an incidence varying from $20 \%$ to $100 \%$, indicating a broad dissemination of geminivirus in these crops in the Lower Basin of San Francisco Valley.
Sintomas típicos de doenças causadas por geminivírus foram observados em plantios de tomateiro (Lycopersicon esculentum Mill.) no Submédio do Vale São Francisco, região situada nos estados de Pernambuco e Bahia, no segundo semestre de 1996. Entre as alterações morfológicas induzidas por geminivírus, as mais comuns são paralisação do crescimento da planta, folíolos pequenos, encarquilhados, coriáceos, com bordos voltados para cima e com mosaico (Lima \& Haji, 1998). Estes sintomas foram verificados em tomateiro, após o aparecimento de populações de mosca branca 
Bemisia argentifolii Bellows \& Perring ou biótipo B de $B$. tabaci Gennadius nessa região, no segundo semestre de 1995 (Haji et al., 1997). Durante o ano de 1997, observou-se um aumento na incidência de geminivírus em vários plantios de tomateiro dessa região, mesmo com a ocorrência de baixas populações de mosca branca. As perdas médias na produção, verificadas nesse período, flutuaram em torno de 30\% (Lima \& Haji, 1998). Atualmente, essas viroses constituem-se no principal problema fitossanitário do tomateiro no Submédio do Vale São Francisco. A presença de geminivírus foi também detectada na cultura do pimentão (Capsicum annuum L.), com incidência de 10 a 20\% (Lima et al., 1999).

Os geminivírus, transmitidos por mosca branca ( $B$. tabaci), têm causado sérios prejuízos em culturas como tomate, feijão (Phaseolus vulgaris L.), cucurbitáceas, pimentão, algodão (Gossypium hirsutum L.) e mandioca (Manihot esculenta Crantz) em regiões tropicais e subtropicais de todo o mundo, constituindo-se em fator limitante à produção. Em tomateiro, perdas significativas vêm sendo registradas desde os anos 80 em países do continente americano, onde cerca de 20 diferentes geminivírus já foram relatados (Polston \& Anderson, 1997).

No Brasil, o primeiro relato de geminivírus em tomateiro foi feito por Costa et al. (1976) que verificaram a transmissão de seis vírus por $B$. tabaci. Com a introdução de $B$. argentifolii nas regiões Sudeste, Centro-Oeste e Nordeste (Haji et al., 1997), novos surtos dessas viroses nessa cultura têm sido observados. Registros de sua ocorrência já foram feitos em tomateiro no Distrito Federal e nos estados de Minas Gerais, Rio de Janeiro, Ceará, Sergipe e Goiás (Faria et al., 2000). No estado de São Paulo, um novo geminivírus, denominado Tomato yellow vein streak virus (TYLCV), foi descrito por Faria et al. (1997). No Submédio do Vale São Francisco, infecção por geminivírus em tomateiro causaram perdas estimadas em até $100 \%$ em algumas áreas (Lima \& Haji, 1998).

Os geminivírus pertencem à família Geminiviridae, sendo constituídos por um genoma de DNA circular de fita simples, encapsidado em partículas geminadas. Segundo a organização do genoma, inseto vetor e planta hospedeira, os geminivírus estão divididos em três gêneros: Mastrevirus, Curtovirus e Begomovirus, denominados anteriormente como Subgrupos I, II e III, respectivamente (Timmermans et al., 1994). O gênero Begomovirus é constituído por vírus transmitidos por mosca branca para dicotiledôneas e que têm causado grandes prejuízos em todo o mundo. Esses vírus possuem o genoma dividido em dois componentes, DNA-A e DNA-B, codificando para um total de seis genes (Lazarowitz, 1992), exceto alguns isolados de Tomato yellow leaf curl virus que tem o genoma constituído por apenas um componente.

Ribeiro et al. (1998) compararam seqüências genômicas parciais de isolados de geminivírus de tomateiros do Distrito Federal, Minas Gerais e do Submédio do Vale São Francisco, detectando seis diferentes espécies ainda não descritas, o que indica a grande variabilidade desses vírus associados à cultura do tomate no Brasil.
Este trabalho teve como objetivos estudar a distribuição de geminiviroses em tomateiro e relatar a detecção destas viroses na cultura do pimentão no Submédio do Vale São Francisco e nos municípios Pesqueira, no Estado de Pernambuco e Mirangaba na Bahia.

No período de outubro de 1996 a dezembro de 1998 foram coletadas 1368 amostras de tomateiro cvs. IPA-5, IPA6, Santa Adélia, Santa Adélia Super e Rio Grande e os híbridos HyPeel, Zenith, TX e Heinz 2710 e 194 amostras de plantas de pimentão cv. S-59 e o híbrido Tango. A coleta foi feita em 120 plantios de 14 municípios, dos quais 12 situam-se no Submédio do Vale São Francisco, totalizando 1.562 amostras (Tabela 1).

As amostras, constituídas por brotos apicais de plantas, exibindo sintomas semelhantes àqueles causados por geminivírus, foram coletadas aleatoriamente dentro da área de plantio, acondicionadas em sacos de plástico individuais e transportadas em caixas de isopor até o Laboratório de Fitopatologia da Embrapa Semi-Árido, Petrolina-PE, onde foram processadas para os testes de detecção viral.

As amostras foram preparadas utilizando-se as metodologias "dot blot" ou "squash blot", segundo Gilbertson et al. (1991) e Rom et al. (1993). Tecido foliar foi macerado e uma gota do extrato, de aproximadamente $10 \mu \mathrm{l}$, foi depositada em membrana de náilon (Genibind $-45 \mu \mathrm{m}$ ) ou um fragmento do tecido foi triturado diretamente sobre a mesma. As membranas contendo as amostras foram tratadas com solução de $\mathrm{NaOH}$ 0,4N (5 min); lavadas em tampão Tris$\mathrm{HCl} \mathrm{pH} \mathrm{7,5} \mathrm{(5} \mathrm{min),} \mathrm{enxaguadas} \mathrm{em} 2$ X SSC (5 min), imersas em etanol $95 \%$ por 5 min (duas vezes) e secas à temperatura ambiente. O DNA do vírus foi fixado à membrana em forno seco à temperatura de $80^{\circ} \mathrm{C}$ por $2 \mathrm{~h}$. A detecção de geminivírus nas amostras foi realizada utilizando-se sondas moleculares (Navot et al., 1989) marcadas com ${ }^{32} \mathrm{P}$, constituídas por DNA dos componentes A completos de Bean golden mosaic virus (BGMV) do Brasil e de Bean golden yellow mosaic virus (BGYMV) da Guatemala para tomate (Gilbertson et al., 1991) ou constituída por um fragmento de DNA do componente A do geminivírus de tomate do Distrito Federal, para as amostras de pimentão (Lima et al., 1999). As sondas foram produzidas com o Kit Ready to go DNA labelling (dCTP) (Pharmacia). As sondas utilizadas são do tipo não específicas e propiciam a detecção de quaisquer geminivírus transmitidos por mosca branca, sem no entanto permitir uma distinção entre diferentes espécies. Após efetuadas as lavagens das membranas, filme de raio-X foi exposto às membranas por um período de $24 \mathrm{~h}$. O autoradiograma obtido foi analisado após revelação. A hibridização foi realizada em condições de média especificidade $\left(50{ }^{\circ} \mathrm{C}\right)$ (Ferreira et al., 1999). Os testes de detecção foram realizados nos Laboratórios de Biologia Molecular da Embrapa Recursos Genéticos e Biotecnologia e Embrapa Hortaliças, Brasília-DF.

Nas 1.562 amostras coletadas, a presença de DNA viral foi confirmada em $908(58,1 \%)$, sendo $823(60,2 \%)$ de tomate e $85(43,8 \%)$ de pimentão (Tabela 1$)$. Naquelas com resultado negativo, pode ter ocorrido uma baixa concentração viral, 
Distribuição de geminivírus nas culturas do tomate e pimentão...

TABELA 1 - Incidência de geminivírus em tomateiro (Lycopersicon esculentum) e detecção na cultura do pimentão (Capsicum anuunn) no Submédio do Vale São Francisco e nos municípios de Pesqueira, em Pernambuco e Mirangaba, na Bahia, em 1996, 1997 e 1998. Embrapa Semi-Árido, Petrolina-PE

\begin{tabular}{|c|c|c|c|c|c|}
\hline Ano/ Local & $\begin{array}{l}\text { Cv. ou híbrido } \\
\text { (n⿳0 de plantios) }\end{array}$ & $\begin{array}{l}\text { Área } \\
\text { (ha) }\end{array}$ & $\begin{array}{c}\text { Idade } \\
\text { (d.a.t.)* }\end{array}$ & $\begin{array}{c}\text { Incidência } \\
\text { estimada (\%) }\end{array}$ & $\begin{array}{c}\mathrm{N}^{0} \text { amostras } \\
\text { positivas } / \mathbf{n}^{0} \text { de } \\
\text { amostras testadas }(\%)\end{array}$ \\
\hline \multicolumn{6}{|c|}{ TOMATE } \\
\hline \multicolumn{6}{|l|}{1996 - Petrolina, PE } \\
\hline Projeto Sen. Nilo Coelho & $\begin{array}{l}\text { IPA-5(1), IPA-6(2), } \\
\text { Sta Adélia (1) }\end{array}$ & $1-2$ & $30-50$ & $80-100$ & $80 / 80(100)$ \\
\hline Projeto Bebedouro & IPA-5(1) & 0,3 & 30 & 100 & $20 / 20(100)$ \\
\hline TOTAL (1996) & 5 plantios $\mathrm{s}$ & & & & $100 / 100(100)$ \\
\hline \multicolumn{6}{|c|}{1997 - Estado de Pernambuco } \\
\hline \multicolumn{6}{|c|}{ Petrolina } \\
\hline Projeto Bebedouro & IPA-5 (3) & $1-2,5$ & $54-61$ & $5-30$ & $6 / 16(37,5)$ \\
\hline Projeto Sen. Nilo Coelho & $\begin{array}{l}\text { o IPA-5 (16), Sta Adélia } \\
\text { (1), HyPeel (3), Heinz } \\
2710(2), \text { Zenith (1) }\end{array}$ & $2-14$ & $15-79$ & $5-100$ & $154 / 366(42,1)$ \\
\hline Pedrinhas & IPA-5(3), Zenith (1) & $2-17$ & 85 & 5 & $20 / 24(83,3)$ \\
\hline$\underline{\text { Sta. Maria da Boa Vista }}$ IP & IPA-5(7), TX(2), Zenith (1) & $1-45$ & $40-86$ & $5-10$ & $21 / 63(33,3)$ \\
\hline Orocó & Sta Adélia (2), IPA-5 (19) & $0,5-10$ & $14-77$ & $5-90$ & $84 / 178(47 \%)$ \\
\hline$\overline{\text { Lagoa Grande }}$ & Santa Adélia Super (1) & 6 & 50 & 80 & $15 / 20(51,7)$ \\
\hline Pesqueira** & IPA-5(1) & 2 & 50 & 70 & $13 / 13(100)$ \\
\hline São José do Belmonte & IPA-5(1) & 3 & 35 & 100 & $20 / 20(100)$ \\
\hline Cabrobó & IPA-5(1) & $0,3-5$ & $45-60$ & $70-100$ & $54 / 58(93,1)$ \\
\hline \multicolumn{6}{|l|}{1997 - Estado da Bahia } \\
\hline Casa Nova & IPA-5 (1) & 4 & 45 & 90 & $14 / 20(70)$ \\
\hline \multicolumn{6}{|l|}{ Sento Sé } \\
\hline Projeto Itapera & IPA-5 (1) & 4,2 & 15 & 5 & $35 / 60(58,3)$ \\
\hline \multicolumn{6}{|l|}{ Abaré } \\
\hline Projeto Pedra Branca & IPA-5 (1) & $1-8$ & $16-72$ & $5-100$ & $45 / 84(53,6)$ \\
\hline \multicolumn{6}{|l|}{$\underline{\text { Juazeiro }}$} \\
\hline Projeto Maniçoba & IPA-5 (4), Zenite (1) & $2-6,5$ & $32-62$ & $10-100$ & $24 / 44(54,5)$ \\
\hline Projeto Mandacarú & IPA-5 (3), Zenith (1) & $3-12$ & $45-51$ & $10-50$ & $6 / 20(30)$ \\
\hline Vale do Salitre & Santa Adélia (1) & 1,5 & 55 & 70 & $20 / 20(100)$ \\
\hline$\underline{\text { Sobradinho }}$ & $\begin{array}{l}\text { IPA-5 (3), Sta Adélia } \\
\quad \text { (2), Rio Gde (2) }\end{array}$ & $0,3-2$ & $45-60$ & $70-100$ & $92 / 98(93,9)$ \\
\hline \multicolumn{6}{|l|}{ Curaçá } \\
\hline Projeto Curaçá & IPA-5 (4), Zenith (1) & $2-10$ & $39-60$ & $10-50$ & $5 / 24(20,8)$ \\
\hline Mirangaba** & IPA-5 (1) & 50 & $46-66$ & $5-30$ & $15 / 60(25)$ \\
\hline TOTAL (1997) & 91 plantios & & & & $643 / 1188(54,1)$ \\
\hline \multicolumn{6}{|l|}{1998 - Orocó, PE } \\
\hline $\begin{array}{l}\text { Projeto Brígida } \\
\text { Abaré, BA }\end{array}$ & IPA-5(4) & $2-4$ & $20-60$ & $5-80$ & $40 / 40(100)$ \\
\hline Projeto Pedra Branca & IPA-5(4) & $1-3$ & $40-80$ & $40-90$ & $40 / 40(100)$ \\
\hline TOTAL (1998) & 8 plantios & & & & 80/80 (100) \\
\hline TOTAL (1996+97+98) & 104 plantios & - & - & - & $823 / 1368(60,2)$ \\
\hline \multicolumn{6}{|c|}{ Pimentão } \\
\hline \multicolumn{6}{|l|}{1998 - Curaçá, BA } \\
\hline $\begin{array}{l}\text { Projeto Curaçá } \\
\text { Petrolina, PE }\end{array}$ & S-59 (10) & $3,0-14$ & $45-60$ & $45-60$ & $38 / 88(43,2)$ \\
\hline Projeto Sen. Nilo Coelho & Tango (6) & $3,0-10$ & $40-50$ & $40-50$ & $47 / 106(44,3)$ \\
\hline TOTAL & 16 plantios & & - & - & $85 / 194(43,8)$ \\
\hline
\end{tabular}

* Dias após o transplante; ** Municípios que não pertencem ao Submédio do Vale São Francisco. 
infecção tardia ou distribuição irregular de vírus na planta. Outra hipótese seria que essas amostras não estivessem infetadas com geminivírus.

A presença de DNA viral foi detectada em amostras coletadas em todos os 120 plantios visitados, correspondendo a cinco cultivares e quatro híbridos de tomateiro e uma cultivar e um híbrido de pimentão, com incidência de 20,8\% a 100\%, confirmada por hibridização (Tabela 1).

Sintomas de geminivírus em tomateiro no Submédio do Vale São Francisco foram observados em 1996, em cultivos mantidos fora do calendário de plantio estabelecido para a região. Em cinco áreas de 0,3 a 2,0 ha, situadas no Projeto Senador Nilo Coelho, Petrolina-PE, plantas das cvs. IPA-5, IPA-6 e Santa Adélia com até 50 dias após o transplante, apresentavam mosaico, enrugamento e redução do tamanho de folíolos. Plantios com 30 dias pós-transplante e exibindo esses mesmos tipos de sintomas foram eliminados devido à alta incidência de geminivírus, o que sugere que a infecção das mudas possa ter ocorrido na fase de sementeira. A presença de DNA viral foi confirmada em 100\% das amostras coletadas nessas áreas em 1996 (Tabela 1).

Elevada severidade de sintomas e expansão de geminiviroses em plantios de tomateiro do Submédio do Vale São Francisco, foram observadas nos anos de 1997 e 1998, com a ocorrência de altas ou baixas populações de mosca branca em campo. A infecção causada por geminivírus foi observada em 25 plantios dos municípios de Petrolina-PE, Sobradinho e Juazeiro-BA, no início de 1997 e posteriormente, ainda neste mesmo ano, essas viroses foram detectadas em 66 plantios de 11 municípios dos estados de Pernambuco e Bahia. Do total de 1.188 amostras de tomateiro coletadas nessas áreas, em 1997, a presença de DNA viral foi confirmada em $643(54,1 \%)$ amostras (Tabela 1; Figura 1). Nessas áreas, os geminivírus não haviam sido registrados em tomateiro no ano anterior. No ano seguinte, 1998, esses vírus foram detectados em oito novas áreas de tomateiro no Projeto Pedra Branca, no município de Abaré-BA e no Projeto Brígida, no município de Orocó-PE, nas quais não haviam sido verificados, em 1997. A presença de DNA viral também foi confirmada por meio de "dot" ou "squash blot" em $100 \%$ das amostras coletadas nesses municípios (Tabela 1). Isto indica a ampla disseminação desses vírus em tomateiro no Submédio do Vale São Francisco.

Perdas significativas na produção têm sido detectadas em tomateiro, devido a alta incidência de geminivírus nessa cultura na região, desde o segundo semestre de 1996. Como conseqüência, a área cultivada com tomate tem sido significativamente reduzida nos últimos dois anos. A cv. IPA5, apesar da alta suscetibilidade às geminiviroses (Ferreira et al., 1999) e às tospoviroses, ainda é muito cultivada. Dentre

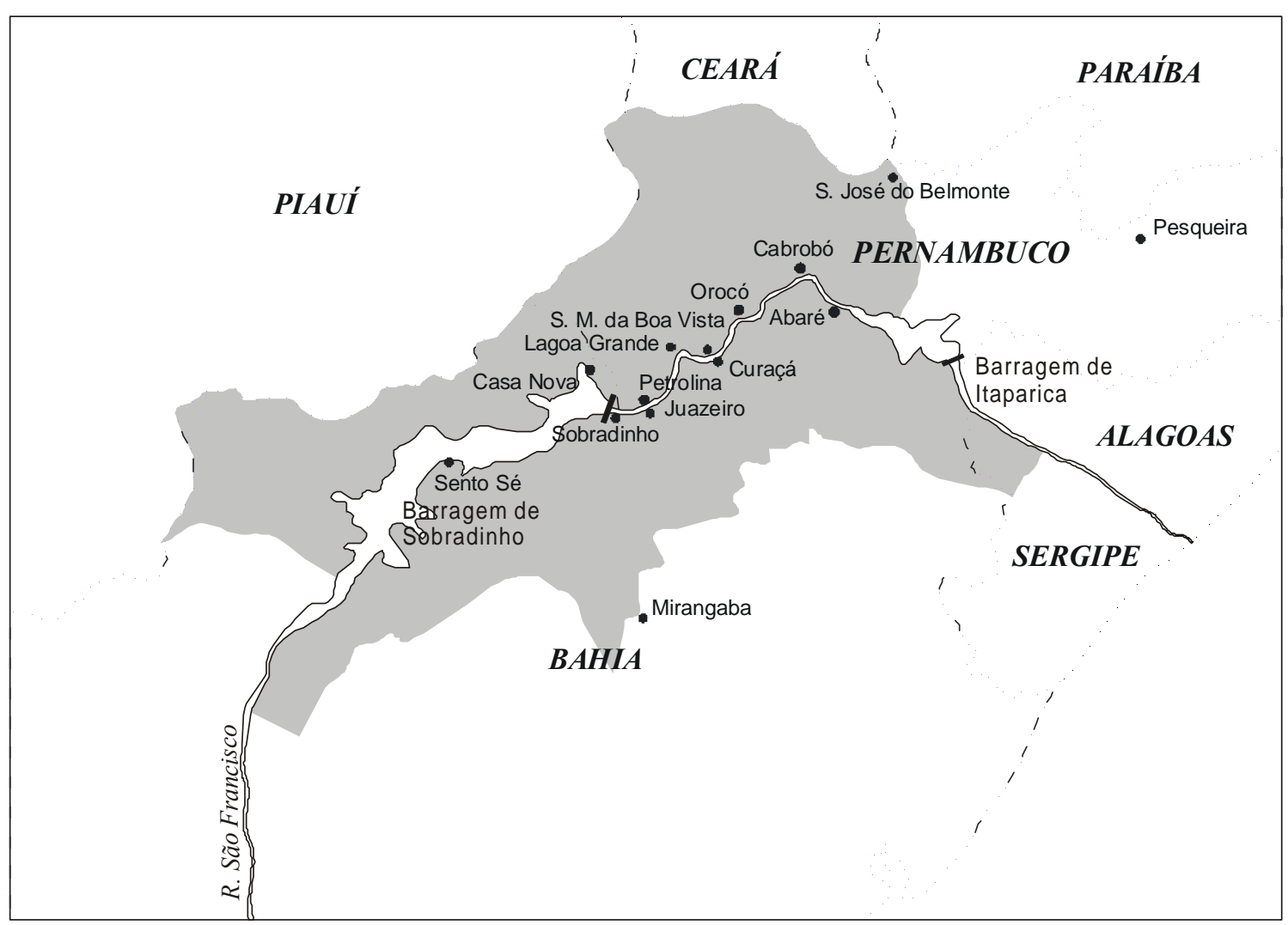

FIG. 1 - Mapa com a localização dos 12 municípios do Submédio do Vale São Francisco e dos municípios de Pesqueira e Mirangaba, nos quais foram feitas as coletas de amostras de tomateiro e de pimentão. (A área escurecida corresponde ao Submédio do Vale São Francisco). 
as áreas amostradas no presente estudo, 79 (76\%) haviam sido plantadas com IPA-5.

Na cultura do pimentão, sintomas de geminiviroses foram observados em 1997 em plantios dos municípios de Curaçá-BA e Petrolina-PE, na cv. S-59, para indústria de páprica, e no híbrido Tango, para consumo in natura. Das amostras de pimentão coletadas 85 amostras $(43,8 \%)$ estavam infetadas por geminivírus (Tabela 1). Esta foi a primeira detecção de geminivírus na cultura do pimentão no Brasil. Um relato preliminar foi publicado por Lima et al. (1999). Ao contrário de geminivírus em tomateiro, isolados obtidos de pimentão ainda não foram caracterizados.

\section{REFERÊNCIAS BIBLIOGRÁFICAS}

COSTA, A.S. Whitefly-transmitted plant disease. Annual Review of Phytopathology 16:429-447. 1976.

FARIA, J.C., SOUZA-DIAS, J.A.C., SLACK, S.A. \& MAXWELL, D.P. A new geminivirus associated with tomato in the state of São Paulo, Brazil. Plant Disease 4:423. 1997. (Note).

FARIA, J.C., BEZERRA, I.C., ZERBINI, F.M., RIBEIRO, S.G. \& LIMA, M.F. Situação atual das geminiviroses no Brasil. Fitopatologia Brasileira 3:125-137. 2000.

FERREIRA, P.T.O., BEZERRA, I.C., VILLAS BÔAS, G.L., RIBEIRO, S.G., GIORDANO, L.B. Avaliação de fontes de resistência a isolados de geminivírus com genoma bipartido transmitido por Bemisia argentifolii em Lycopersicon spp. Fitopatologia Brasileira 24:131-135. 1999.

GILBERTSON, R.L., FARIA, J.C., HANSON, S.F., MORALES, R.T., AHLQUIST, P., MAXWELL, D.P. \& RUSSEL,D.R. Cloning of the complete DNA genomes of four bean-infecting geminiviruses and determining their infectivity by electric discharge particle acceleration. Phytopathology 81:980-985. 1991.
HAJI, F.N.P., LIMA, M.F. \& ALENCAR, J.A. de. Mosca branca no Brasil. Anais, $7^{\circ}$ Taller Latino-Americano y del Caribe sobre moscas blancas y geminivirus, Santo Domingo, Republica Dominicana. 1997. p.5-7.

LAZAROWITZ, S.G. Geminivirus: genome structure and gene function. Critical Reviews in Plant Sciences 4:327349. 1992.

LIMA, M.F., BEZERRA, I.C., RIBEIRO, S. G. \& de ÁVILA, A.C. Detection of sweet pepper whitefly-transmitted geminivirus in the "Submédio" of San Francisco Valley. Programa e Resumos, $22^{\circ}$ Congresso Paulista de Fitopatologia, Jaboticabal, SP. 1999. p.106.

LIMA, M.F. \& HAJI, F.N.P. Mosca branca x geminivírus na cultura do tomate no Submédio do Vale do São Francisco. Horticultura Brasileira. 15: contracapa. 1998.

NAVOT, N., BER, R. \& CZOSNEK, H. Rapid detection of tomato yellow leaf curl virus in squashes of plants and insect vectors. Phytopathology 79: 562-568. 1989.

POLSTON, J.E. \& ANDERSON, P.K. The emergence of whitefly-transmitted geminiviruses in tomato in the Western Hemisphere. Plant Disease 12:1358-1369. 1997.

RIBEIRO, S.G., de ÁVILA, A.C., BEZERRA, I.C., FERNANDES, J.J., FARIA, J.C., LIMA, M.F., GILBERTSON, R.L., MACIEL-ZAMBOLIM, E. \& ZERBINI, F.M. Widespread occurrence of tomato geminiviruses in Brazil, associated with the new biotype of the whitefly vector. Plant Disease 82:830. 1998. (Note).

ROM, M., ANTIGNUS, Y., GIDONI, D. \& PILOWSKY, M. Accumulation of tomato yellow leaf curl virus DNA in tolerant and susceptible tomato lines. Plant Disease 77:253-257. 1993.

TIMMERMANS, M.C., PREMDAS, O.E. \& MESSING, J. Geminiviruses and their uses as extrachromosomal replicons. Annual Review of Biochemistry and Molecular Biology 45:79-112. 1994. 